\title{
Personal Responsibility for Cardiac Health: What are the Ethical Demands?
}

\section{Responsibility}

The concept of responsibility, commonplace and untroubling in many areas of life, provokes controversy when it comes to health and healthcare. We frequently assign responsibility to agents in a variety of contexts: sporting achievements, criminal actions, valued friendships and performance at work. Yet discussion of whether or not people are responsible for an illness they suffer as a result of actions they have taken (or not taken) soon risks looking like 'victim blaming'.

There are three related but different concepts. Causal responsibility for an outcome refers to the part one plays in bringing about an outcome. Moral responsibility for that outcome requires that one caused, at least in part, that outcome but also that one had knowledge of the possibility and control over one's actions. Moral responsibility thus requires that an outcome is foreseeable and avoidable. Blameworthiness is a function of moral responsibility and the degree of harm. We will discuss moral responsibility for health.

There are three broad approaches which often arise in response to questions about whether or not people are responsible for their health (see Table 1).

1. The personal-responsibility model. This assumes that, since it is common to think that people's health-related behaviour (what they choose to eat, how much they drink, how often they exercise, whether they smoke, and so on) are often within the agent's control, they are indeed responsible for those behaviours. Exceptions may be made where a lack of control for instance, due to addiction - can be established, in which case an agent may be excused from responsibility. If agents are responsible we may be justified in holding them responsible (e.g. rewarding or punishing them) for their behaviour. There are two general justifications for this. First, consequentialist: patients will do better (have better health outcomes) if they adopt healthier behaviours. Consequentialism is a family of ethical theories (including utilitarianism) which state that the right act is the one with the best consequences. Systems of rewards and punishments can change behaviour and bring about such good consequences. Second, desert: those who adopt healthy behaviours are more deserving of support (e.g. healthcare) than those who do not, since their suffering was simply due to bad luck rather than free choice. We should prioritise the unlucky over others according to a theory known as 'luck egalitarianism'.

2. The no-responsibility model. This approach assumes that people are not typically capable of controlling their health-related behaviour in the way required for responsibility. This could be claimed on the basis that it is much harder to control one's health-related behaviour than 
those behaviours people are normally considered responsible for (such as punishable acts like theft). Alternatively, it could be that we often overestimate the range of things people are responsible for. In this case, systems of punishment for crimes, or systems of reward for sporting achievement, are a mistake; people are not really responsible for committing crimes or winning races. Sceptics about free will and responsibility in general would fit in here.

3. The social model. This proposes that institutions and groups bear more responsibility for the health-related behaviours of individuals than do individuals themselves. They need not claim that individuals are completely free or responsibility (e.g. for smoking), but that other institutions (e.g. tobacco companies) bear more responsibility. This means that any responsibility-focused interventions ought to focus on those social institutions rather than on individuals.

\begin{tabular}{|l|l|}
\hline Model & Implications \\
\hline $\begin{array}{l}\text { Personal- } \\
\text { responsibility }\end{array}$ & $\begin{array}{l}\text { People are responsible for their health; differential treatment may be } \\
\text { justified on consequentialist or desert-based grounds. }\end{array}$ \\
\hline No-responsibility & $\begin{array}{l}\text { People are not (typically) responsible for their health and differential } \\
\text { treatment is wrong. }\end{array}$ \\
\hline Social & $\begin{array}{l}\text { Social institutions bear the bulk of responsibility for health-related } \\
\text { behaviour and health and any responsibility-sensitive policies should } \\
\text { target institutions rather than individuals. }\end{array}$ \\
\hline
\end{tabular}

Table 1: Summary of models of responsibility.

\section{Responsibility for Heart Health}

Each of these models could be applied to heart health, where people's behaviour can influence their future cardiovascular health. Consider those who are hypertensive, and thus at increased risk of suffering heart disease, heart attack, stroke, and so on. NHS advice is to make various dietary changes including ensuring salt intake is below $6 \mathrm{~g}$ per day; if overweight, to lose weight; to engage in regular physical activity; to quit smoking; and to reduce alcohol and caffeine consumption. People may also need to adhere to blood pressure lowering medications such as ACE inhibitors [1].

The personal-responsibility model suggests that, although challenging, people are capable of enacting the changes recommended above. This implies people can exercise responsibility over such behaviours as salt intake or medication adherence. This means that it 
makes sense to offer this advice in the first place: that people who want to protect their long term heart health can do so, as long as they are informed of the actions they need to take. It also suggests something further, that perhaps those who fail to adopt these behaviours are blameworthy if harmful consequences arise as a result. Such harmful consequences include heart disease and the suffering the patient will experience, as well as harms to others (such as their friends and family) if they become ill, the costs to the health service of providing subsequent treatment, or other patients who are denied limited resources such as heart transplants.

In contrast, the no-responsibility model suggests that people with hypertension who fail to adopt recommended risk-lowering behaviours are not responsible, and not blameworthy. This could be because people typically lack information about the salt content of food they and are not able to reduce this, or they face significant obstacles to weight loss because lasting dietary changes are so difficult. Here, the demands of responsibility are too high, or the challenges of achieving the behaviours recommended for hypertensives too severe, to consider people responsible for any health (and other) harms that result from their behaviour.

Finally, the social model points to social influences on behaviour which proponents argue supersede individual responsibility. They might point to the importance of salt content of ready meals or restaurant-cooked food in determining how much salt people consume, or the lack of accessible green space as a barrier to taking exercise. The social model suggests that institutions are responsible for the harms heart disease causes an agent (and others) to suffer, and it is appropriate to apportion blame to food retailers or local government rather than individuals. Sugar and other "sin" taxes operate partly through the social model, though they also cause individuals to internalise the costs of their behavior (which assumes the personal-responsibility model).

\section{Policy Implications}

Depending on which model of responsibility for heart health is adopted, different policy implications will follow. These can come from (1) practical considerations and (2) ethical considerations. The first include factors like the cost-effectiveness of different polices. So, on the personal-responsibility model, since people are capable of altering their behaviour in ways that will promote future cardiac health, public health campaigns that inform people about how to do so will be worthwhile; on the no-responsibility model, unless specific barriers to responsibility are noted and addressed, then providing people with information is unlikely to result in uptake of 'healthier' behaviours. The ethical considerations focus on what it would be fair or appropriate to do. In this case, if the social model is correct, then institutions such as tobacco companies and governments might be responsible for preserving people's health, and thus have a moral 
obligation to do so. Failing to fulfil this obligation could justify penalties and other punishments for those institutions. Likewise, on the no-responsibility model, it would never be appropriate to punish failures to adopt healthy behaviours (for instance, by deprioritising people on heart transplant waiting lists or refusing them treatment) because patients are deemed not responsible for those failures on this model.

There is some indication that responsibility is thought to be appropriate in the context of healthcare in the UK, and that the personal-responsibility model is at least partly at work. For instance, the NHS Constitution for England states:

The NHS belongs to all of us. There are things that we can all do for ourselves and for one another to help it work effectively, and to ensure resources are used responsibly... [including recognising] that you can make a significant contribution to your own, and your family's, good health and wellbeing, and take personal responsibility for it. [2]

In some areas of healthcare, patients are deprioritised for treatment if they fail to make 'healthy' behavioural changes, which could be influenced by beliefs about responsibility [3, 4]. Other possible responsibility-sensitive policies are given in Table 2. But on the other hand, the NHS largely adopts a strategy of seeking to maximise cost-effectiveness, on the basis of providing treatment according to need, without regard to responsibility. This suggests something like the no-responsibility or social models are also at work.

\begin{tabular}{|l|l|}
\hline Domain & Possible Responsibility-Sensitive Policy \\
\hline Organ allocation & $\begin{array}{l}\text { Preferentially allocate organs to those whose behaviour } \\
\text { did not contribute to their disease }\end{array}$ \\
\hline $\begin{array}{l}\text { Elective surgery (e.g. hip } \\
\text { replacement) }\end{array}$ & $\begin{array}{l}\text { Prioritise those who do not smoke and are not obese for } \\
\text { surgery sooner }\end{array}$ \\
\hline GP appointments & Fine patients who fail to attend appointments \\
\hline
\end{tabular}

Table 2: Possible responsibility-sensitive policies, based on the personal-responsibility model.

But which model is correct? There is plenty of scope for debate here, and it will depend, in part, on the precise requirements one thinks are necessary in order for an agent to be considered responsible for a particular action or omission. Medical ethicists have often argued that there 
are conceptual, ethical and practical objections to the personal-responsibility model, and often advocate something closer to the no-responsibility or social models [5-9] though there are also plenty of examples where ethicists adopt something closer to the personal-responsibility model [10-12]. Some ethicists have argued that the personal-responsibility model can be used in a prospective way if patients are given "golden opportunities" to change behavior, or lifestyle contracts [13]. Both empirical evidence regarding different influence on people's behaviour, and ethical understanding of the value, requirements, and implications of responsibility are needed in order to adjudicate this debate. 


\section{Bibliography}

1. NHS. Overview - High blood pressure (hypertension). 2019 [cited 2020 21/09/2020];

Available from: https:/www.nhs.uk/conditions/high-blood-pressure-hypertension/.

2. NHS England, The NHS Constitution for England. 2015. p. 1-12.

3. Royal College of Surgeons, Smokers and overweight patients: Soft targets for NHS savings? 2016, Royal College of Surgeons.

4. Brown, R.C., Irresponsibly Infertile? Obesity, Efficiency, and Exclusion from Treatment. Health Care Analysis, 2019. 27(2): p. 61-76.

5. Brown, R.C.H., Moral responsibility for (un)healthy behaviour. Journal of Medical Ethics, 2013. 39(11): p. 695-698.

6. Brown, R.C.H., Resisting Moralisation in Health Promotion. Ethical Theory and Moral Practice, 2018. 21(4): p. 997-1011.

7. Eyal, N., Denial of Treatment to Obese Patients - the Wrong Policy on Personal Responsibility for Health. 2013: p. 1-4.

8. Friesen, P., Personal responsibility within health policy: unethical and ineffective. Journal of Medical Ethics, 2017. 44(1): p. 53-58.

9. Levy, N., Taking responsibility for responsibility. Public Health Ethics, 2019. 12(2): p. 103113.

10. Glannon, W., Responsibility, alcoholism, and liver transplantation. Journal of Medicine and Philosophy, 1998. 23(1): p. 31-49.

11. Buyx, A.M., Personal responsibility for health as a rationing criterion: why we don\&apos;t like it and why maybe we should. Journal of Medical Ethics, 2008. 34(12): p. 871-874.

12. Callahan, D., Obesity: Chasing an Elusive Epidemic. Hastings Center Report, 2012. 43(1): p. 34-40.

13. Savulescu, J., Golden opportunity, reasonable risk and personal responsibility for health. Journal of Medical Ethics, 2018. 44(1): p. 59-61. 